\title{
Imágenes del otro: colombianos y extranjeros en el cine contemporáneo de ficción
}

\author{
Manuel Silva Rodríguez
}

Recibido: 20 de febrero de 2012 Aprobado: 27 de marzo de 2012

\begin{abstract}
Resumen
A partir de un modo de entender la relación cine e identidad, el artículo indaga en las imágenes con las cuales se representan, en un corpus de filmes recientes, los personajes colombianos cuando entran en contacto con personajes foráneos en territorio colombiano o extranjero. Desde la perspectiva de la imagología, el texto pretende identificar estereotipos y lugares comunes con los cuales son representados los colombianos y, por extensión, Colombia.
\end{abstract}

Palabras clave: alteridad, cine colombiano, cine e identidad, extranjeros, imagología, nación.

* La investigación fue desarrollada en la Escuela de Comunicación Social de la Universidad del Valle, Grupo de investigación en sonido, imagen y escritura audiovisual Caligari, entre septiembre de 2009 y junio de 2010. Su objetivo general fue realizar un estudio sobre la representación de la identidad colombiana ante otras culturas en un corpus de producciones y coproducciones cinematográficas colombianas de ficción realizadas entre 1999 y 2009.

** Doctor en Teoría de la Literatura y Literatura Comparada de la Universidad Autónoma de Barcelona. Magíster en Filosofía y Comunicador Social de la Universidad de Antioquia, Medellín-Colombia, Profesor asociado Escuela de Comunicación Social, Universidad del Valle, Cali, Colombia. Correo electrónico: manuel.silva@correounivalle.edu.co. 


\title{
Images of the Others: Colombian Citizens and Foreigners in Contemporary Science Fiction Film
}

\begin{abstract}
Base on a way of understanding the film-identity relationship, this article makes inquiries about the images through which Colombian characters are performed in a corpus of recent films, when they get in touch with foreign characters both in Colombia and abroad. From an imagology point of view, the article is intended to identify stereotypes and common places with which Colombian characters and Colombia as a country are performed.
\end{abstract}

Key words: Alterity; Colombian film; film and identity; foreigners; imagology; nation. 


\section{Introducción}

Este artículo presenta resultados de la investigación Imágenes del otro: Representaciones de la identidad colombiana ante otras culturas en producciones y coproducciones cinematográficas colombianas de ficción realizadas entre 1999 y 2009. En él se exponen elementos del marco teórico de la investigación como algunos desarrollos conceptuales sobre la noción de identidad, algunas de sus singularidades cuando refiere la construcción de identidades nacionales y el papel que el cine puede desempeñar en este proceso. El artículo pone el acento en la cinematografía de ficción y en el reconocimiento que se le da en la política pública a la injerencia de esta industria cultural en la construcción de discursos identitarios. El texto, además, precisa que sigue la línea de investigación de la imagología, indica el corpus estudiado y sus criterios de análisis. Por último, el artículo presenta algunas conclusiones sobre lo apreciado en las películas.

\section{Sobre la noción de identidad}

La noción de identidad adoptada en este texto recoge planteamientos de, entre otros, Stuart Hall (1996), Zygmunt Bauman (1999, 2001 b) y Fernando Aínsa (1986). Esta noción subraya que la identidad -en términos más precisos las identidades- se constituye en el ámbito del discurso y se configura en la conjunción de, por lo menos, dos elementos: la representación de sí y la presencia de la alteridad.

En efecto, Stuart Hall (1996) sintetiza una posición teórica que hoy es de uso corriente: el concepto de identidad ha sido despojado de sentidos y valores esencialistas. En lugar de entenderla así, la identidad ha pasado a ser considerada como un predicado cambiante, expuesto a propósito de una forma de existencia y vinculado a unas condiciones históricas. Siguiendo a Foucault, Hall apunta que la cuestión de la identidad vino a ser pensada como "el proceso de sujeción a las prácticas discursivas" (1996: 15), o sea, como la identificación con uno u otro discurso. Aunque, según Hall, al igual que el concepto de identidad el de identificación no está exento de dificultades; este es preferible que aquel porque hace evidente que la identidad es la identificación con una o varias prácticas discursivas y, en consecuencia, con el modo como estas son constitutivas de la acción.

Al acto de "identificarse con", por otro lado, le es inherente un sentido negativo: "identificarse con" es correlato de "diferenciarse de", de "no identificarse con". Esta diferenciación otorgará relieve a ese o eso que no se es, a lo que no se parece a la idea que de sí se forma un sujeto, a lo diferente, al "otro", a la alteridad. Este reconocimiento de la alteridad ha dado lugar a que esta sea valorada como elemento constitutivo de la identidad. Vincular la existencia a un discurso que marca la diferencia con otros discursos es, al mismo tiempo, establecer distancias con otras existencias. Esta situación muestra que adoptar una identidad puede ser a la vez un proyecto -si se persevera en ella, si se quiere conservarla- y un proceso de exclusión. "Identificarse con" es establecer un adentro y un afuera: "Las identidades se construyen a través de la diferencia, no al margen de ella. [...] A lo largo de sus trayectorias, las identidades pueden funcionar como puntos de identificación y adhesión solo debido a su capacidad de excluir, de omitir, de dejar "afuera"" (Hall, 1996: 18). Dicho de otra manera: adoptar un discurso es postular un orden y a partir de él construir la realidad.

Ahora bien, el "otro" cuenta no solo porque es aquella instancia respecto de la cual un sujeto ocupa una posición. El otro también cuenta porque, como el espejo lacaniano, nos devuelve una imagen de nosotros. El resultado de este movimiento es que la representación que construimos de nosotros implica aquella imagen, la que "ellos", los "otros", han forjado de nosotros. Como asegura Fernando Aínsa, "la "representación" que una sociedad se hace de sí misma no basta para configurar su identidad. Es necesario -y muchas veces en forma 
abiertamente contradictoria- integrar esta representación con la idea que los "demás", es decir, los integrantes de "otros grupos culturales", se hacen de "esa" identidad" (1986: 30). Entonces, ¿cómo nos ve el otro?, ¿qué dice de nosotros?, ¿con qué nos identifica?, ¿qué somos para él?, ¿̇desde dónde nos mira? De acuerdo con el otro en el que nos miremos tendremos una u otra imagen nuestra. Por eso, como destaca Aínsa, la relación con el otro puede ser contradictoria. Incluso, antes que caracterizarse por la armonía, a la relación con el otro usualmente la marca la confrontación. La imagen de nosotros que el otro nos devuelve pocas veces nos complace, no siempre corresponde con el concepto que tenemos de nosotros.

Por otra parte, establecer que la "identificación con" y en general la construcción de la identidad acontecen en el ámbito discursivo es reconocer que estos procesos ocurren en el territorio del lenguaje. "Identificarse con" o "identificar a otro con" es vincular una forma de existencia con predicados, imágenes y símbolos. "Las identidades, en consecuencia, se construyen dentro de la representación y no fuera de ella" (Hall, 1996: 17). "Identificarse con", entonces, es construir una representación de un sujeto, ya sea de sí mismo o de otro. Si las identidades se construyen dentro de la representación, cabe preguntar entonces: ¿dónde cobran cuerpo esas representaciones?, ¿en cuáles producciones discursivas las encontramos? Como señala Aínsa, aunque la identidad sea discurso necesita mostrarse: "los pueblos, como los individuos, necesitan una "cristalización" del concepto para poder representarse a sí mismos y ante los demás" (1986: 29). Es en este contexto donde el cine, como tantas otras producciones culturales, halla un lugar significativo.

\section{Sobre la identidad de las naciones}

Como lo destaca B. Anderson (1983), la creación de los Estados-nación a finales del siglo XVIII en Europa -proceso replicado poco después en América- supuso un esfuerzo por agrupar en un nuevo orden formal los antiguos grupos sociales y las culturas locales que, bajo los modelos feudal y monárquico, se encontraban dispersos en el territorio y gozaban de cierta autonomía. A este respecto, Martín-Barbero (1998) y Bauman (1999) recuerdan que, además de la violencia física, esta empresa acarreó un gran despliegue de recursos para imponer un orden simbólico sobre aquella diversidad preexistente. La adopción de una sola lengua, una sola religión, un solo sistema medicinal son ejemplos de ello. Donde antes predominaban la diversidad y la dispersión, con la instauración de ese orden formal llamado Estado-nación se imponía la necesidad de crear un sentido de pertenencia y unidad, es decir, un sentido de comunidad, una identidad colectiva. Esto es, como sostiene Bauman citando a Jack Young, "'La identidad se inventa justo cuando se colapsa la comunidad"” (2001b: 22).

Benedict Anderson entiende este proceso como la construcción de una realidad imaginaria: la nación. Según este autor, la nación es una "comunidad política imaginada" producto de un cruce de fuerzas históricas: "Es imaginada porque aun los miembros de la nación más pequeña no conocerán jamás a la mayoría de sus compatriotas, no los verán ni oirán jamás hablar de ellos, pero en la mente de cada uno vive la imagen de su comunión" (1983: 23).

La definición de Anderson es importante porque define a la nación como una comunidad y porque precisa que se trata de una comunidad imaginada. Entendemos, con autores como Zygmunt Bauman (2001b) y Jean-Luc Nancy (1986), que el sentido atribuido a la comunidad no corresponde a una existencia fáctica sino a la concepción compartida de un ideal: la comunidad como el sueño de un espacio familiar, el anhelo por mantener un ámbito de relaciones armónicas. Desde este punto de vista, en tanto que comunidad la nación es un anhelo. Se hace comprensible, entonces, la afirmación de Anderson según la cual la nación "se imagina como comunidad 
porque, independientemente de la desigualdad y la explotación que en efecto puedan prevalecer en cada caso, la nación se concibe siempre como un compañerismo profundo, horizontal" (1983: 25).

Vista así, la nación es una idea compartida alrededor de la cual se crean unos lazos, un sentimiento de unidad y pertenencia. Es una comunidad imaginada porque, como lo resalta Anderson, la totalidad de quienes participan de esa idea y de ese sentimiento no se conocen, no mantienen una comunicación directa. Aunque el conocimiento entre todos sus miembros no es posible, su unidad sí puede serlo por el sentimiento de unión creado por el hecho de haber nacido en o adoptado como propio un territorio y por compartir unos valores asociados a ese espacio. Los elementos de ese conjunto se sienten parte de él porque creen en unos lazos que los unen, "en la mente de cada uno [de los miembros] vive la imagen de su comunión" (1983: 23).

Decir que esa unidad es imaginaria no significa que ella carezca de fuerza o que no mantenga relación con el orden histórico. En cuanto un grupo se reconoce como comunidad alrededor del sentimiento de unión se establecen unas fronteras, un adentro y un afuera que diferencia aquellos que pertenecen de aquellos que no. De ahí que Anderson también defina la nación como una comunidad que se imagina limitada (1983: 25). O sea, la nación establece unos límites entre propios y extraños, entre nacionales y extranjeros según los términos jurídicos.

\section{El extranjero: una forma de alteridad}

Y justamente en el mundo contemporáneo los extranjeros se han constituido como una de las principales encarnaciones de los extraños, de una forma de alteridad. El extranjero, la imagen que de él se tiene, es actualmente una de las formas de alteridad que más incide en la configuración de los discursos identitarios tanto para las personas nativas de un país como para los inmigrantes: "El concepto de extranjería, de otredad, solo se explica a partir de la existencia de una figura opuesta: la identidad" (Blank-Cereijido, Yankelevich, 2003: 14). No obstante, en ese doble movimiento de afirmación de lo "propio" o "interno" y de introducción de lo "ajeno" o "externo" el aumento de las migraciones ha llevado a que la presencia de extranjeros en distintos territorios genere diversos tipos de reacciones: desde las políticas y las prácticas que abogan por la "integración" y el multiculturalismo, hasta sus versiones contrarias que defienden los nacionalismos más extremos y el racismo so capa de proteger los derechos civiles y económicos de los ciudadanos nacidos en determinado país.

Estas actitudes, sin embargo, no son nuevas. En una aproximación a la historia del término, Blanck-Cereijido y Yankelevich explican que la "palabra extranjero contiene la raíz griega xénos y su enunciado expresa el desprecio y extrañeza que suscita lo que se considera extraño, ajeno, bárbaro, indeseable, aunque algunas veces el extraño pueda ser amado y admirado" (2003: 22). Estos autores, al igual que Sennett (1978) y Bauman (2001a), entre otros, cuando analizan las reacciones negativas que desencadena la presencia de los extranjeros en un territorio remiten al sentimiento de amenaza que el extraño despierta en la comunidad. En efecto, en estos casos el extranjero es visto como un agente perturbador, como una presencia que desestabiliza el orden y los sentimientos de familiaridad y seguridad despertados por la pertenencia a una comunidad.

Lo anterior contribuiría a explicar el rechazo y el señalamiento del extranjero como la manifestación de un sentimiento de temor frente a aquello que rompe la imagen unitaria de la comunidad: "La creación de otro o la depositación de ciertos caracteres en el otro proviene de la necesidad de proteger la coherencia de la propia imagen" (Blanck-Cereijido, Yankelevich, 2003: 28). De ahí que estos autores sostengan que "[e]n el fondo, [el término extranjero] responde a una necesidad 
de identificación, una catalogación que trata de explicar o cuestionar aquello que por su naturaleza diverge de los usos de una comunidad. Con ello surge la figura del otro, a través del cual se filtra nuestra propia identidad" (2003: 13).

Ahora bien, la actitud adoptada frente al extraño no es necesariamente la del rechazo. La antigua práctica de ver al desconocido como un útil o como algo exótico sigue vigente. Bauman (2001a: 99-112) recuerda estas reacciones cuando analiza los comportamientos que en las ciudades modernas muestran distintos grupos sociales en su relación con los extranjeros. La actitud frente a los extranjeros no siempre es igual porque se los encasilla en diversas categorías. En los países de la Comunidad Europea, por ejemplo, existen categorías como las de poseedores de pasaportes comunitarios y extracomunitarios. Si bien entre los europeos se reconocen diferencias, estas no son las mismas que se observan en relación con los asiáticos, los latinoamericanos y los africanos.

Las diferencias también se han resuelto a través de la elusión. Evitar, mantener a una prudente distancia al extranjero es uno de los comportamientos adoptados frente a esos otros que pueden resultar incómodos. Bauman sostiene que "Im|ientras se mantenga la libertad de movimiento y el "poder de evitación", la presencia de extraños no constriñe, irrita ni confunde, mientras las oportunidades de experiencias variadas y apasionantes que ofrece dicha presencia sean bien recibidas y se goce de ellas" (2001a: 106). No se trata aquí solo de la reducción de los extranjeros a ocuparse de los oficios que los naturales de un país no desean realizar. Al extraño se le puede permitir acercarse mientras sea proveedor de experiencias seductoras: "Para algunos residentes de la ciudad moderna, seguros en sus hogares a prueba de robo de los barrios residenciales, en sus oficinas fortificadas de los centros comerciales plagados de policías, con sus coches llenos de artilugios de seguridad que los llevan de casa a la oficina y viceversa, el "extraño" es tan agradable como una playa de surf y en absoluto amenazador" (Bauman, 2001a: 106).

Esta perspectiva desvela que los extraños pueden ser convertidos por los "naturales" de un lugar en fuente de experiencias placenteras, en objeto exótico para admirar y para insertarlo en los circuitos del consumo. Así, "integrados" al sistema económico "los extraños son personas a las que uno paga por los servicios prestados y por el derecho a prescindir de sus servicios una vez que ya no aportan placer. [...] En esa vida, los extraños son proveedores de placeres" (Bauman, 2001: 106 107).

Este modo de clasificar a los extranjeros, de fijarles un lugar y un uso de acuerdo con su origen y con las conveniencias de una comunidad, remite a las representaciones que se construyen de ellos, a los sistemas de prejuicios característicos de las formaciones sociales. En efecto, Blanck-Cereijido y Yankelevich afirman que el prejuicio es "la parte inconsciente de la ideología de una sociedad, (es el) conjunto de sentimientos, juicios y actitudes que provocan y justifican medidas discriminatorias, separación, segregación, y explotación de un grupo por otro" (2003: 24).

Y esos sentimientos, juicios y valores se fomentan y se sostienen a través de la circulación y el uso de discursos; de crear una imagen de la nación, de señalar, ya sea de manera consciente o no, cuáles valores -traducidos en juicios, creencias, costumbres, actos, etc.- corresponden y cuáles no con aquello que en un momento determinado debe servir de punto de convergencia a los miembros de la comunidad. Y es aquí donde de nuevo encontramos el cine como fuente de producción y circulación de discursos que representan a la nación y a los otros.

\section{Cine e identidad}

Entre otros, autores como Carlos Monsiváis (2000) y Antonio Paranaguá (2003) recuerdan el 
papel que el cine jugó en distintos momentos del siglo XX en la afirmación de los sentimientos de nación en distintas naciones de América Latina. Por ejemplo, en referencia a la representación del paisaje mexicano en el cine hecho en ese país en la primera mitad del siglo XX, Monsiváis apunta: "A la nación soñada entre disparates y aciertos casi involuntarios, cuyo nombre también es México, la caracterizan el perfil rural, los paisajes bellísimos, las tragedias que interrumpen los besos, y los charros que pasan sus días a caballo mientras un trío los acompaña a campo traviesa" (2000: 59). Y Paranaguá, señalando la función que cumplió el cine durante varias dictaduras populistas, afirma: "Quizá pueda verse en el cine un laboratorio para los nacionalismos y populismos contemporáneos. Así como la "revolución lexicográfica" precedió a los nacionalismos europeos, la revolución cinematográfica fue un laboratorio para las comunidades imaginadas por el populismo latinoamericano" (2003: 222-223).

Por su parte, Martín-Barbero llamó la atención en cuanto en América Latina "el cine va a conectar con el hambre de las masas por hacerse visibles socialmente. Y se va a inscribir en ese movimiento poniendo imagen y voz a la "identidad nacional". Pues al cine la gente va a verse [... $\mid$ Y al permitir al pueblo verse, lo nacionaliza. No le otorga nacionalidad, pero sí los modos de resentirla" (1998: 223). Desde una perspectiva histórica, entonces, podemos anotar que las imágenes que ha entregado el cine proporcionan modos de sentir lo nacional, esto es, lo que se asocia -ya sea de manera consciente o no- con lo característico y propio de una nación.

En el caso de Colombia, el modo como nos ven es históricamente la primera situación puesta entre interrogantes con la llegada del cinematógrafo al país. Pedro Zuluaga, por ejemplo, reproduce una nota de prensa de 1899 en la cual un cronista caleño del diario El Ferrocarril manifiesta su descontento por algunas imágenes cinematográficas de su ciudad:
Nos permitirá el empresario unas observaciones (...) que suprima las vistas de calles y edificios de Cali; pues parece que no han sido tomadas con bastante arte: la del puente, por ejemplo, ¿por qué no se tomó de manera que se vieran las hermosas ceibas? y la de San Francisco, de manera que se vieran su frontis ó su interior (reproducción fotográfica de un fragmento de prensa, en Zuluaga, 2007: 19).

La lectura contemporánea de productos de aquel momento nos permite, además, observar que en el período del cine silente la ficción y el documental sirvieron al propósito de proyectar una imagen deseada del país. O, más exactamente, la imagen del país y del estamento social, económico y político al cual pertenecían aquellos que tenían los recursos y el poder suficientes para realizar o encargar la realización de películas.

En efecto, en ese período el cine de ficción también aportó a la configuración de imágenes de la nación. Así lo testifican películas -o lo que queda de ellas- como El drama del 15 de octubre (1915), María (1922), Aura o las violetas (1924), Bajo el cielo antioqueño (1926), Alma provinciana (1926) o Garras de oro (1926). Como lo había hecho la literatura en el siglo XIX, en el XX la nueva factoría de ficciones y entretenimiento emergía para ganarse un lugar en el mercado de las representaciones. La afirmación de lo propio y, por extensión, la demarcación de lo extraño o lo que se deseaba superar en un país ansioso de modernidad también venían a determinar parte del contenido de la nueva práctica artística. La presencia en los contenidos cinematográficos de ciertos elementos materiales, espacios, personajes, situaciones, conflictos y relaciones, entre otros factores, dan cuenta de cómo los productores y autores de las películas se veían a sí mismos y cómo veían a los otros, cómo querían ser vistos y reconocidos.

Posteriormente, adoptando y adaptando formas de hacer cine, las producciones colombianas asumieron como propia "la realidad" del país. 
Así, por ejemplo, dice el crítico Oswaldo Osorio: "En Colombia también se aprendió la lección del neorrealismo [...]. Por primera vez en las pantallas del país se pudo ver al colombiano del común, con sus problemas, su cotidianidad y en espacios reconocibles por el público común" (2010: 11).

Y el cine reciente -ya sean producciones colombianas, coproducciones o incluso realizaciones extranjeras- no ha sido ajeno a esta situación. En el caso de la temática de la relación de los colombianos con extranjeros, si bien hay antecedentes en filmes como Visa USA (Lisandro Duque, 1986) o La nave de los sueños (Ciro Durán, 1996), la migración y sus avatares es uno de los temas abordados con cierta frecuencia por diversas producciones cinematográficas de la última década. Para ser más concretos, en mayor medida la inmigración de colombianos a Estados Unidos y en menor medida el paso de extranjeros por Colombia han constituido la materia de distintas películas recientes. Igualmente, la participación de actores y actrices colombianos en largometrajes realizados en el exterior ${ }^{1}$, las novelas o textos de escritores colombianos adaptados al cine por guionistas y directores nacionales y extranjeros ${ }^{2}$ y cierto éxito comercial de películas como María llena eres de gracia (2004) y Paraíso Travel (2008), entre otros hechos, llaman la atención sobre la relativa frecuencia con la cual se ha proyectado una u otra imagen de los colombianos en un conjunto de largometrajes de reciente factura. En esos filmes y en otros de menor impacto mediático es posible detectar unos rasgos que, desde el dominio de la ficción, configuran un discurso sobre la identidad colectiva, sobre las maneras de ver a los colombianos y a las colombianas en su condición de

1 Recordemos los casos recientes de actrices como Juana Acosta en A golpes con la vida (2005), Angie Cepeda en Oculto (2005) y en El mal ajeno (2010), Flora Martínez en Canciones de amor en Lolita's club, y Martina García en, entre otras, Rabia (2010) y La cara oculta (2012), quienes interpretan a mujeres colombianas en películas españolas y de productores extranjeros.

2 Por ejemplo La virgen de los sicarios (Barbet Schroeder, 2000), Perder es cuestión de método (Sergio Cabrera, 2005), Rosario Tijeras (Emilio Maillé, 2005), Satanás (Andrés Baiz, 2007), El arriero (Guillermo Calle, 2009). extranjeros y sobre el modo de ver en Colombia a otros países y a los extranjeros.

Si comparada con otras tradiciones cinematográficas la colombiana posee un bajo índice de películas ${ }^{3}$, es cierto también que en los últimos años en Colombia se ha incrementado la producción y la coproducción de filmes ${ }^{4}$. Aunque no ha sido el único factor influyente, a este hecho ha contribuido sobre todo la Ley 814 de 2003, conocida como la Ley de Cine, que estableció una serie de condiciones para fomentar la producción cinematográfica en el país. Como evidencia del interés que el Estado ha puesto en la industria cinematográfica, hoy el Ministerio de Cultura lleva estadísticas actualizadas no solo de las producciones y coproducciones colombianas, sino también del número de espectadores por película con el consolidado por año desde 1996. El Ministerio, asimismo, reconoce que "[l]a política cinematográfica colombiana se basa en el reconocimiento de que "el cine constituye una expresión cultural generadora de identidad social", que se fundamenta en la diversidad étnica y cultural del país, y como tal debe ser protegida y apoyada por el Estado" ". Se acepta así la importancia estratégica de la industria cultural cinematográfica.

En efecto, la cinematografía es considerada una de las industrias culturales de mayor potencial en América Latina y en el país. Tal potencial comprende el factor económico. Esto es, el reto de enfrentar el monopolio de la industria estadounidense gracias a la reducción de los costos merced a las nuevas tecnologías, a la diversidad de soportes y a la multiplicidad de canales de circula-

3326 desde 1915 hasta diciembre de 2009, según las estadísticas del Ministerio de Cultura. Véase: http://www.mincultura.gov. $\mathrm{co} /$ ?idcategoria $=18374$

4 Entre 1999 y 2009, según datos del Ministerio de Cultura, en nuestro país se estrenaron 84 películas clasificadas como colombianas, una cifra inédita si se compara este periodo con cualquier otro de la historia de nuestra cinematografía.

5 Cfr. El Compendio de políticas culturales del Ministerio de Cultura, disponible en http://www.mincultura.gov.co/index. php?idcategoria $=34153$. Véase también el Documento de Política cinematográfica del Ministerio, disponible en http://www.mincultura.gov.co/index.php?idcategoria $=36190$ 
ción y difusión, ya sean formales e informales. Pero también implica la inversión en Colombia de capitales extranjeros, la creación de unas condiciones internas para la producción y de un mercado para la industria. Y en ese marco se localiza también el factor cultural, en cuyo orden el cine, si se compara con la literatura y otras prácticas artísticas, sigue manteniendo un lugar privilegiado como agente implicado en la construcción de referentes identitarios y de memoria histórica. Al respecto, cabe citar al investigador Octavio Getino, quien sostiene que "América Latina, representa, al menos potencialmente, un espacio altamente favorable para el desarrollo de industrias del audiovisual con las que podría mejorar los procesos identitarios y los imaginarios de cada pueblo" (2007).

Así las cosas, el cómo nos mostramos, cómo somos vistos y cómo vemos a otros en el cine son cuestiones que siguen manteniendo vigencia, aunque hoy se abordan en un orden sociocultural diferente.

\section{El corpus estudiado y los criterios de análisis}

El trabajo que aquí se presenta abordó un corpus de ocho películas, relacionadas con los temas del extranjero y de la migración, que fueron producidas y coproducidas en el país o que contaron con alguna participación de recursos colombianos. El corpus lo conforman:

El séptimo cielo (Juan Fischer, 1999)

María llena eres de gracia (Joshua Marston, 2004)

Colombianos, un acto de fe (Carlos Fernández, 2004)

El Colombian Dream (Felipe Aljure, 2006)

El trato (Francisco Norden, 2006)

Paraíso Travel (Simón Brand, 2008)

Dr. alemán (Tom Schreiber, 2008)

El arriero (Guillermo Calle, 2009)
El trabajo se situó en la perspectiva de la imagología, una línea de investigación que se pregunta por la construcción de la imagen del extranjero como el "otro". En principio, la imagología se presentaba como la indagación realizada en torno a la construcción de imágenes y estereotipos sobre un país o una cultura en una literatura nacional. Sin embargo, los estudios culturales han encontrado en esta línea de investigación un dominio teórico y metodológico que han ampliado, trasladándolo del campo de la literatura al de producciones culturales como el cine. Como lo precisa Nora Moll,

... por imagología se entiende, pues, el estudio de las imágenes, de los prejuicios, de los clichés, de los estereotipos y, en general, de las opiniones sobre otros pueblos y culturas que la literatura transmite, desde el convencimiento de que estas imágenes, tal y como se definen comúnmente, tienen una importancia que va más allá del puro dato [...]. El objetivo principal de las investigaciones imagológicas es el de revelar el valor ideológico y político que puedan tener ciertos aspectos de una obra [...] precisamente porque en ellos se condensan las ideas que un autor comparte con el medio social y cultural en que vive (2002: 349).

Para establecer esas imágenes en el análisis se reconocieron los roles y las funciones que desempeñan los personajes, se atendió la dimensión espacial de los relatos, pues en ella, en la dicotomía entre lo propio y lo ajeno, lo nacional y lo internacional, se desarrollan las tramas de las películas y, por último, en los niveles estructural y temático se observó el carácter de los conflictos que dominan las tramas.

\section{A modo de conclusión: algunas imágenes}

La configuración de referentes identitarios en las ficciones analizadas se sitúa en un marco espacio-temporal contemporáneo, al cual remiten los contenidos de las películas. Este marco se caracteriza por la construcción del espacio colombiano e internacional, en el que grandes 
ciudades como Nueva York (María llena eres de gracia, Paraíso travel, El séptimo cielo), Madrid (El arriero), Bogotá (María llena eres de gracia, Colombianos, un acto de fe, El trato), Barranquilla (El arriero), Cali (Dr. alemán) y Medellín (Paraíso travel), y poblaciones más pequeñas como Girardot (El colombian dream) o el pueblo no nombrado de María llena eres de gracia son representadas con el ritmo, las urgencias económicas, las transformaciones y las demandas de la vida contemporánea. Es decir, en esta construcción del espacio también reconocemos la contemporaneidad de la dimensión histórica de las películas en virtud de los problemas, los usos del espacio, los consumos, las actividades que realizan los personajes y sus deseos. Elementos narrativos como los conflictos generados por el desempleo, la migración, el narcotráfico, la guerra y la violencia urbana que vive el país remiten al espectador a un contexto que le es familiar.

En estas películas países como Estados Unidos, España, Inglaterra, Canadá o Argentina son escenarios alternativos a Colombia, son figuras de la alteridad frente a la cual, según los filmes, los colombianos miran su país. En estas ficciones la construcción imaginaria de cada uno de estos países como figuras de la alteridad se funda en idealizaciones, en relatos fragmentarios o en rumores. Esas figuras de la alteridad son, en principio, más fruto de la imaginación de los personajes que de su experiencia. Por ejemplo, en María llena eres de gracia, la visión imaginada más explícita de Estados Unidos, la encontramos cuando María pregunta a Lucy, una de las mulas que hacen el viaje con ella, "¿cómo es eso por allá?" Sin vacilar, Lucy responde: "Eso... es demasiado perfecto. Todo es recto". No obstante, por lo que ella cuenta, sabemos que Lucy habla desde la experiencia que le reportan dos cortos viajes a Nueva York en calidad de mula. Aún así afirma que aquello es demasiado perfecto. En Colombianos un acto de fe Canadá es el lugar donde uno de sus protagonistas puede realizar los deseos que no se materializan en Colombia. Juan -profesional convertido en taxista- se ilusiona porque en aquel país ofrecen "todas las posibilidades para instalarse. Y necesitan profesionales". Y como sucede con él, también ocurre con el hijo suyo que está por nacer. Al futuro colombiano le hace ilusión el cambio: "Ser ciudadano canadiense. Bueno, así sí valdría la pena venir a este mundo. Ser ciudadano del primer mundo". Y en Paraíso travel, mientras señala una fotografía de Nueva York, Reina le dice a Marlon "mirá cómo se pone eso allá todo bonito con la nieve, en vez de ese barrial tan hijueputa que se arma acá cada vez que llueve".

La construcción imaginaria de países que encarnan formas de la alteridad está determinada prácticamente por la variable económica. En las películas esos escenarios alternativos con los cuales los colombianos confrontan su país son seleccionados en función de lo que se cree que ofrecen sus economías. En un mundo globalizado, se deduce de los filmes, la economía es el factor principal sobre el cual se instauran relaciones de alteridad. Los "otros" son países a los cuales se atribuye una economía mejor, un mercado laboral más fuerte o un mercado de consumidores de droga. Según los contenidos de las ficciones, resulta claro que una economía doméstica débil más la globalización económica y el narcotráfico como parte de esta inciden en la permanencia de los ciudadanos en su país de origen, en las imágenes que ellos construyen de otros países, en el tipo de relaciones sociales que establecen y, por lo tanto, en la selección y construcción de referentes identitarios.

Como ejemplo de ello en El séptimo cielo vemos que la ocupación de Joselito, el protagonista, consiste en encontrar un trabajo en el que se sienta cómodo. Por su parte, su madre tiene una doble ocupación: además de atender su casa, limpia tres apartamentos. En María llena eres de gracia Javier trafica con cocaína a Estados Unidos. Pero cuando conoce a María él no se presenta como traficante: en un juego de simulaciones y eufemismos Javier le dice a María "te vamos a dar unos rollos de fotografía" y allá "revelamos los rollos y en 5 o 10 días 
estás de nuevo aquí". María acepta la propuesta y cuando viaja no es enviada sola. La película pone el acento en que son mujeres, dos de ellas jóvenes obreras de un pueblo, las que el narcotráfico utiliza para transportar droga al exterior.

Y en la parte de esta película que transcurre en Estados Unidos, las actividades a las cuales se dedican los personajes muestran cómo se prolongan en los inmigrantes colombianos los modos de subsistencia presentes en la representación de la economía del país. Por un lado intervienen dos matones, de acento colombiano, encargados de recibir a las mujeres en Nueva York. Ellos son empleados de la industria del narcotráfico: mientras sus pares en Colombia tienen como propósito enviar a Estados Unidos la droga a como dé lugar, ellos tienen allá el objetivo de recuperar de cualquier modo la totalidad de la cocaína que lleva cada mujer. Y, por otro lado, vemos el mundo de Carla -hermana de Lucy- y su círculo. Carla es el reflejo de lo que aguarda a María. No es claro cuál es el trabajo de Carla. Sí, en cambio, el de su esposo y el primo de este: uno es conductor para una empresa y el otro es panadero. Por mediación de Carla aparece un personaje que desempeña un oficio singular: Fernando, una especie de agente de cooperación, cuya labor consiste en colaborar para la ubicación laboral de inmigrantes indocumentados y la resolución de algunos problemas que a ellos se les presentan.

Cuando se hace tránsito del "otro imaginado" al "otro conocido" las películas tienden a deshacer la idealización y a sustituirla por la resignación y la perseverancia en creer que en el futuro hay algo mejor. El viaje como secuencia de amenazas y pruebas de supervivencia, las vejaciones, la explotación laboral o la incomunicación se muestran, en un primer momento, como experiencias introductorias en un nuevo orden. En María llena eres de gracia, Paraíso travel, El trato y El arriero el viaje tiene ese sentido. Luego, en el caso de quienes no regresan, una dudosa integración a ese orden se representa como un proceso de asimilación de las nuevas condiciones, a veces gracias al cambio parcial, por lo que los inmigrantes pasan a llevar una vida diferente. Vida signada por el miedo, si recordamos un diálogo de Paraíso travel: "¿Cómo me quito este miedo?", pregunta Marlon a su auxiliador Hernando, y la respuesta que recibe es que "es cuestión de tiempo. Los inmigrantes llevamos el miedo y la incertidumbre adentro. Creemos que siempre hay alguien persiguiéndonos".

En efecto, en casi todas las películas la imagen de los colombianos es la de personas que no entran en diálogo con los otros. Cuando analiza las comunidades que se guarecen para protegerse de los extraños, Bauman sostiene que "comunidad significa mismidad, en tanto que "mismidad" significa la ausencia del Otro, especialmente de otro obstinadamente diferente" (2001b:137). Esta es la tendencia de la representación de los colombianos en el exterior. Si no ensimismada, se representa como una comunidad aislada. Los personajes colombianos aparecen replegados en una especie de gueto que se abre eventualmente y eso, sobre todo, para dar acceso a aquellos que resultan menos extraños porque hablan la misma lengua o porque se trata de relaciones limitadas a la esfera laboral. La comunidad rota y abandonada en el territorio nacional se trata de restablecer luego, en tierra ajena, y de mantener a través de la referencia a la nacionalidad y del uso de algunos nombres y símbolos que sirven de vínculo colectivo.

Muestra de lo anterior está en El séptimo cielo, donde la bandera colombiana pende en la puerta del armario de Joselito y de Mario, su hermano. Joselito, que solo se relaciona con colombianos y dominicanos, le dice a Mario que su novia pertenece a otro mundo porque ella es estadounidense. En Paraíso travel los colombianos o están con sus paisanos o excepcionalmente con otros latinos. En esta película y en María llena eres de gracia, por lo demás, buena parte de las acciones transcurren en Queens, el "barrio colombiano" de Nueva York. En El arriero la relación entre Ancízar, el traficante 
colombiano, e Iñaki, su socio madrileño que lo deja tirado cuando las cosas se ponen mal, no va más allá de un vínculo instrumental por parte del español. Por lo demás, Ancízar siempre se rodea de sus mujeres colombianas o cuanto más se apoya en Roger, su confidente barranquillero.

En ese sentido, cuando la figura de la alteridad es considerada desde la perspectiva de los individuos se reafirma que el trabajo es un factor decisivo. De nuevo, las actividades económicas y laborales determinan el tipo de personajes con los que se relacionan los colombianos. Y dado que los nexos sociales parecen limitados al ámbito de las ocupaciones, en la mayoría de los casos los personajes colombianos representan la paradoja de encontrar en el "otro" una suerte de copia de sí. Si bien no se puede aseverar que se trata de una homología absoluta, el hecho es que por tratarse de relaciones sostenidas en un ámbito social restringido la similitud ocupacional resulta ser el principal -si no el único- elemento de contacto. Por eso vemos a los delincuentes colombianos interactuar fundamentalmente con otros delincuentes, a los "sin papeles" con otros sin papeles o con antiguos sin papeles, a los traficantes de drogas con otros traficantes de drogas. Se representa, en última instancia, un círculo vicioso, una reproducción en el exterior de la condición social adquirida en el lugar de origen, con el añadido de que por fuera de su país los personajes ostentan la cualidad de extranjeros. Así, por ejemplo, En El arriero, El colombian dream y El trato el narcotráfico es el eje de la relación entre los personajes colombianos y los españoles, los sicilianos y los estadounidenses y los ingleses, respectivamente. En Paraíso travel y María llena eres de gracia, los indocumentados constituyen una suerte de fraternidad.

Los anteriores componentes de las películas muestran una representación de los colombianos como extranjeros, reincidente en la marginalidad, la ilegalidad, la precariedad, la violencia y el narcotráfico. Estos elementos indican que los colombianos en el exterior son, en parte, representados como una anomalía social para las sociedades a las cuales ingresan. En otros casos, congruente con un planteamiento de Bauman, los colombianos son "tolerados" mientras guardan la distancia y se ocupan de ciertos oficios. Esta clase de inmigrantes constituyen piezas útiles en los marcos sociales y culturales en los cuales se insertan, personas relegadas a realizar trabajos desdeñados. Así, en Paraíso travel y El séptimo cielo Nueva York es la ciudad cuyos retretes limpian los colombianos. O también donde sobreviven en oficios diversos, como Roger en Paraíso travel, la versión colombiana del pícaro nacional en el primer mundo. En otros casos, las mujeres colombianas son proveedoras de experiencias placenteras y fugaces demandadas por los habitantes de esos espacios. Ahí encontramos las prostitutas: la caleña voluptuosa y la paisa interesada que hacen de su cuerpo su medio de sustento.

Por otra parte, es pertinente considerar la representación de las relaciones que se dan entre los colombianos y los extranjeros en Colombia. Encontramos dos imágenes contradictorias entre sí. Por un lado, una actitud complaciente, casi idólatra, y, por otro, una actitud adversa, casi hostil. En Paraíso travel, por ejemplo, aunque pasa casi inadvertida se cuenta la presencia de un extranjero en Medellín. Se trata de un personaje llamado el "Alemán", el esposo de la tía de Marlon a quien Reina roba los dólares para emprender el viaje a Estados Unidos. El "Alemán" es un hombre mucho mayor que su esposa. Es casi un figurante en un par de escenas. Empero, su presencia cobra relevancia por el significado que él tiene para su esposa colombiana: ella se ufana de haber conseguido casarse con un extranjero, de que el alemán la llevará de luna de miel a un lugar nunca imaginado y de que sus amigas, siempre mordaces por su soltería, rabiarán de la envidia.

En este punto hay que destacar que, en relación con las demás películas, Dr. alemán tiene un rasgo particular. En este filme el encuentro de los 
colombianos con un personaje y con la cultura de otro país no acontece en el exterior o por el breve tránsito de un extranjero por Colombia. En esta película un alemán se instala en Cali. A diferencia de las otras historias, en esta sí vemos a personajes colombianos interactuar por largo tiempo con un individuo de una cultura no latina. En los primeros contactos que Marc, el protagonista, tiene con colombianos, la señora de la familia a donde llega le dice que "qué bueno que usted ya habla español" y Méndez, el médico jefe del hospital, lo saluda así: "como dicen en su país, Heil Hitler". Aunque Méndez, siempre cáustico con el alemán, agrega enseguida: "No preste atención a eso. Cuando yo salgo de mi país me dicen Pablo Escobar". La relación entre Méndez y Marc, desde ese momento, siempre será tensa. En distintas ocasiones Méndez no pierde oportunidad para incomodar de algún modo a Marc. ¿Por qué? Quizá parte de la respuesta está en la escena en la cual Marc entra por primera vez al hospital y Méndez le pregunta si tiene experiencia en atender heridos con armas. En lugar de contestar con un sí o un no, Marc responde de esta manera: "En Alemania está prohibido cortar el césped los domingos. Y nadie lo hace para no molestar a los vecinos". Méndez, entonces, responde que para él, para Marc, el mejor lugar es donde están: las urgencias de un hospital público.

En Dr. alemán la condición de extranjero de Marc es una suerte de imán para que el personaje atraiga una serie de situaciones extraordinarias en relación con las que viven los demás personajes. A Marc lo buscan, lo seducen, le roban, lo amenazan. Por lo que en cada caso asocian con él como extranjero, unos se lo disputan y otros lo rechazan. Méndez, incluso, explica la estancia de Marc como pasante en un hospital caleño en que luego de su paso por Cali este sabe de niños sicarios y de taxistas ladrones y eso es algo interesante para contar a los nietos. Y al final de la película -uno se pregunta si también por él ser extranjero- luego de que Marc mata a un sicario un policía le entrega su pasaporte y le permite marcharse.
En El trato, cuya intrincada trama incluye la historia de un falso documental inglés sobre el tráfico de drogas desde Colombia, el productor extranjero paga a los colombianos para hacer con ellos lo que a bien tenga. John María, el protagonista, resume así el núcleo de la relación: "como los ingleses son los del billete, hay que llevarles la corriente". Cuando el enredo del falso documental es delatado al diario The Chronicle, sus periodistas, interpretados por actores colombianos, viajan a Bogotá y conocen todos los detalles de la farsa. Entonces, después de algunos diálogos pintorescos en los que los colombianos ofrecen "coffe, misters" y sostienen que por plata se hacen pasar hasta por el Papa, los ingleses invitan a una despedida a un lugar tópico: una discoteca de salsa. Allí un episodio anecdótico mantiene el pintoresquismo: los ingleses se deleitan viendo el baile de una morena mientras se dicen que si se la llevan a casa. Y luego, cuando uno de ellos sale a bailar con una de las mujeres que John María llevó para la ocasión, un borracho se siente menospreciado por "el gringo hijueputa" que no le acepta una copa de licor. Aunque el inglés explica que no bebe, el borracho se empeña en salvar su honor colombiano con un revólver.

En las películas analizadas encontramos, pues, la incorporación en sus tramas de una serie de elementos reincidentes, de prejuicios y estereotipos: los colombianos en el exterior son asociados con la ilegalidad, la marginalidad, la explotación, la prostitución, la violencia, el hacinamiento y, en medio de todas las calamidades, la esperanza. Por esto los personajes y las situaciones reiterados: putas, traficantes, rebuscadores, explotados. A estas imágenes se contraponen las de ciertos lazos de solidaridad surgidos del paisanaje y las del afecto familiar, hecho sentir vía telefónica o en el hacinamiento de un cuarto. La imagen de los colombianos, además, es la de un grupo integrado, si acaso, en el mundo productivo, pero resguardado dentro de los límites de su lengua y de sus costumbres. 
Si la pregunta por la construcción de los referentes identitarios no se piensa desde la perspectiva de los colombianos en el exterior sino de lo que acontece en Colombia, las imágenes halladas son en gran medida un correlato de lo que se muestra de ellos cuando están fuera. Constituyen constantes la debilidad de la economía, la precariedad laboral, el desempleo, la venalidad, la ausencia de escrúpulos, el narcotráfico, la ilegalidad, la búsqueda del dinero fácil, el sometimiento de las mujeres y la brutalidad. Son atributos que se mantienen cuando los colombianos interactúan entre sí o cuando lo hacen con extranjeros. Sí se advierte, no obstante, una diferencia: en Colombia los mafiosos tienen más para vivir que el resto de los mortales, y por eso se han convertido en una suerte de modelo social. Este hecho da lugar a uno de los temas reiterados en las películas: el narcotráfico y su meta -transformada en valordel enriquecimiento rápido como una marca que ha impregnado a los distintos sectores de la sociedad, ya se trate de clases sociales o de grupos etarios. Según se aprecia, ese propósito ha permeado la sociedad y se ha convertido en motor y justificación de todo tipo de conductas. Y no solo de la sociedad colombiana, pues en un mundo con una economía globalizada el narcotráfico es una bisagra que une, a través de la ilegalidad y la violencia, a Colombia y a los colombianos con otros países.

Y cuando la ilegalidad y el tráfico de drogas no sirven de nexo para crear relaciones con los otros, la imagen del otro con frecuencia es la de un ser sobreestimado, como sucede con Marc en Dr. alemán o con los ingleses en El trato. En estos casos se advierten rezagos del colonialismo, pues en las ficciones el extranjero no es tratado por la mayoría de los colombianos como una persona más, frente a él se adopta cierto servilismo interesado o, por el contrario, él es objeto de desconfianza y rechazo. Al mismo tiempo, como se advierte en estas mismas películas, las ficciones también construyen una imagen del extranjero como un agente que dirige al colombiano una mirada desde arriba.

Por otra parte, estas películas muestran una fuerte atomización de la sociedad. La dimensión de lo público se representa fragmentada, rota, y cada individuo, o cuanto más cada pequeño núcleo social, actúa en beneficio de su propio interés. Por esta razón, las películas exponen la imagen de una lógica social autodestructiva, según la cual, como apunta Bauman (1999) cuando analiza los extremos a los que ha llevado el individualismo contemporáneo, las soluciones privadas se erigen en la única respuesta para enfrentar el fracaso de un modelo de lo público. Cuando ese horizonte del país se mira desde la perspectiva de distintas generaciones, encontramos visiones que hablan de ese fracaso aún cuando quieren pintar ese futuro posible con un tono de esperanza. Los mayores viven en una sociedad a la cual le han entregado la vida, una sociedad que ha sido incapaz de cumplir con las promesas de bienestar que alguna vez hiciera (Paraíso travel, Colombianos, un acto de fe, El séptimo cielo, El arriero); los jóvenes viven absortos en el ritmo frenético del hedonismo consumista, de las drogas, del dilema de la explotación laboral o del desempleo (Paraíso travel, El colombian dream, María llena eres de gracia, El trato, Dr. alemán); y los padres de los que están por nacer depositan el futuro en la fe en que el estado de cosas cambiará, en la huida hacia países de Jauja o en la aceptación cínica del actual orden local (Paraíso travel, Colombianos, un acto de fe, María llena eres de gracia, El colombian dream).

A lo anterior, se debe agregar que las películas hacen visible la presencia de un discurso social según el cual la pobreza determina y permite justificar todo tipo de comportamientos: en Colombia y en el exterior. De ahí parece derivar un determinismo que explicaría la reproducción de un orden en el que mujeres, negros, niños y pobres estarían destinados a ocupar lugares marginales y a realizar actividades degradantes: aquí y allá. El hecho, aunque paradójico y controversial, es que 
al mostrar esas situaciones de manera testimonial y mimética, al terminar las historias con finales reconciliados y esperanzadores, las ficciones no parecen cuestionar ese orden, parece que les basta con mostrarlo sin entrar a discutirlo.

A finales del siglo XX, la investigadora Catalina González afirmó que "[n]o es posible, entonces, pensar en la construcción de la identidad en este siglo, sin reconocer que una parte de ella está determinada por la relación mediática con el otro. Por lo que "los otros piensan de nosotros", es decir su construcción simbólica, su "imaginario" acerca de nuestra identidad; o -en la dirección contraria- por el "relato" de identidad que los medios enuncian de nosotros" (1997: 79). En el caso planteado aquí, no es que las películas decreten definitivamente que los colombianos "son esto", "son así", son de la forma como los muestran aquí y allá. Las películas son relatos de país, proporcionan imágenes para la elaboración de los distintos relatos que construyen los distintos sectores de la sociedad. Ellas representan modos posibles de ser y, por lo tanto, de los colombianos pensarse, de pensar sobre otros y de que otros piensen sobre ellos. Y si bien junto al cine son muchas otras las producciones y las prácticas culturales que inciden en la construcción de representaciones de distintos sujetos colectivos, no sobra decir que en la comunicación de un ser posible hecho por el cine de ficción también se pone en juego la creación de imágenes compartidas que intervienen en la estructuración de creencias y en el ordenamiento del espacio social y simbólico.

\section{Referencias bibliográficas}

AÍNSA, Fernando. Identidad cultural de Iberoamérica en su narrativa. Madrid: Gredos, 1986.

ANDERSON, Benedict. Comunidades imaginadas. México: FCE: 1993 (1983).

BAUMAN, Zygmunt. La posmodernidad y sus descontentos. Madrid: Akal, 2001 (1997).
BAUMAN, Zygmunt. En busca de la política. Buenos Aires: FCE, 2001 (1999).

BAUMAN, Zygmunt. La sociedad individualizada. Madrid: Cátedra, 2001a.

BAUMAN, Zygmunt. Comunidad: en busca de seguridad en un mundo hostil. Madrid: Siglo XXI, 2003 (2001b).

BLANCK-CEREIJIDO, Fanny; Yankelevich, Pablo. El otro, el extranjero. Madrid: Libros de El Zarzal, 2003.

HALL, Stuart, 1996. "Quién necesita identidad". En: Hall Stuart, Du Gay Paul (comps.). Cuestiones de identidad cultural. Buenos Aires: Amorrortu, 2003, pp. 13-39.

MARTÍN-BARBERO, Jesús. De los medios a las mediaciones. Bogotá: CAB, 1998.

MARTÍNEZ, Pardo Hernando. Historia del cine colombiano. Bogotá: editorial América Latina, 1978.

MONSIVÁIS, Carlos. Aires de familia. Cultura y sociedad en América Latina. Barcelona: Anagrama, 2000.

MOLL, Nora, 2002. La imagología: definición y terminología. En: Gnisci Armando. Introducción a la literatura comparada. Barcelona: Crítica, 2002, pp. 347-389.

NANCY, Jean-Luc. La comunidad desobrada. Madrid: Arena libros, 2001 (1986).

OSORIO, Oswaldo. Realidad y cine colombiano. Medellín: Universidad de Antioquia, 2010.

PARANAGUÁ, Antonio. Tradición y modernidad en el cine de América Latina. Madrid: FCE, 2003.

SENNETT, Richard. El declive del hombre público. Buenos Aires: Península, 1978.

ZULUAGA, Pedro Adrián. iAcción! Cine en Colombia. Bogotá: Museo Nacional de Colombia, 2007.

\section{Cibergrafía}

GETINO, Octavio (2007). Desafíos de la industria del cine en América Latina y el Caribe. En http://www.ehu.es/ zer/zer22/ZER\%2022 _ getino. Consulta en enero de 2009. 
http://www.cancilleria.gov.co. Consulta en abril de 2010

http://www.ciudadviva.gov.co/julio06/magazine/4/index.php. Consulta en abril de 2010

http://www.mincultura.gov.co/index.php?idcategoria $=34153$. Consulta en abril de 2010

http://www.mincultura.gov.co/index.php?idcategoria $=36190$. Consulta en abril de 2010

\section{Filmografía}

El séptimo cielo (Guión y dirección Juan Fischer, USA y Colombia, 1999).
María llena eres de gracia (Guión y dirección: Joshua Marston, USA y Colombia, 2004).

Colombianos un acto de fe (Guión y dirección: Carlos Fernández de Soto, Colombia, 2004).

El colombian dream (Guión y dirección: Felipe Aljure, Colombia, 2006).

El trato (Guión y dirección: Francisco Norden, Colombia y Francia, 2006).

Paraíso travel (Director: Simon Brand, USA, 2008).

Dr. alemán (Director: Tom Schreiber, Alemania, 2009).

El arriero (Guión y dirección: Guillermo Calle, Colombia y España, 2009). 